\title{
Electrocatalytic determination of anti-hyperthyroid drug, methimazole, using a modified carbon-paste electrode
}

\author{
Fahimeh Jalali ${ }^{1 *}$, Loghman Miri ${ }^{1}$ and Mahmoud Roushani ${ }^{2}$ \\ ${ }^{1}$ Department of Chemistry, Razi University, Kermanshah, 67346, Iran. \\ ${ }^{2}$ Department of Chemistry, Faculty of Science, Ilam University, Ilam, Iran.
}

Accepted 14 September, 2012

\begin{abstract}
The preparation and electrochemical behavior of a carbon-paste electrode modified with an oxovanadium (IV) Schiff-base complex was studied. The modified electrode showed efficient catalysis in the electrochemical oxidation of methimazole (MMZ), an anti-hyperthyroid drug. The catalytic effect was observed for $\mathrm{V}^{\mathrm{III}}$ oxidation peak which was produced via disproportionation of $\mathrm{V}^{\mathrm{IV}}$ in acidic solution. The diffusion coefficient (D) of MMZ and the rate constant of catalytic reaction $(k)$ were estimated by chronoamperometry. Determination of MMZ was carried out using differential pulse voltametry. A linear dynamic range of $9 \times 10^{-7}$ to $1 \times 10^{-4} \mathrm{M}$ with a detection limit of $8 \times 10^{-7} \mathrm{M}$ and a limit of quantitation of 2.6 $\times 10^{-6} \mathrm{M}$ was resulted for the drug. The relative standard deviation for determination of $20 \mu \mathrm{M}$ of the drug was found to be $1.7 \%$. The method was used for the quantitation of MMZ in pharmaceutical formulations successfully.
\end{abstract}

Key words: Methimazole, determination, tablets, modified-carbon paste electrode.

\section{INTRODUCTION}

Methimazole, MMZ (1-methyl-2-mercaptoimidazole, tapazole), is an orally taken drug used in the therapy of hyperthyroidism (over activity of the thyroid gland). The chemical structure of the drug is shown in Scheme 1. Its action is to slow down iodide integration into tyrosine and thus, inhibits the production of thyroid hormones (Edward, 1992). MMZ is used as a drug to manage hyperthyroidism associated with Graves' disease, but it has side effects such as possible decrease of white blood cells (Kendall-Taylor, 1984). The drug has also been employed to promote growth in animals for human consumption. It has been reported that MMZ may also cause side effects such as nephritis, liver cirrhosis, skin irritation, allergies and pharyngitis with fever (Edward, 1992).

Several analytical methods have been described for the determination of MMZ, such as high-performance liquid

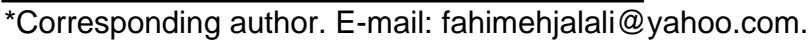

chromatography (Blanchflower et al., 1997; Kusmierek and Bald, 2007), gas chromatography-mass spectrometry (Zhang et al., 2005), flow-injection analysis with chemiluminescence detection (Economou et al., 2004), spectrophotometry (Jovanovic et al., 1992), fluorescence probe method (Dong et al., 2009) and gold nanoparticlecatalyzed chemiluminescence reaction (Sheng et al., 2011). Electrochemical methods, due to their advantages such as high sensitivity, high speed, and low-cost have been used in pharmaceutical analysis for a long time. Analysis of MMZ has been done by using modified electrodes such as glassy carbon electrode modified with multi-walled carbon nanotubes (Xi et al., 2010), an electrode modified with acetylene black/chitosan film (Yazhen, 2011), and a carbon paste electrode modified with a cobalt Schiff base complex (Shahrokhian and Ghalkhani, 2008).

Compared to conventional electrodes, chemically modified electrodes offer unique well-recognized advantages in electrocatalysis, especially in situations where the target analyte requires high over-potential, or 
the sensitivity is low. This characteristic of chemically modified electrodes arises from the combination of conventional electrochemical techniques with the chemical, structural and other specific properties of the modifying layer(s).

Among the modified electrodes those which include inorganic complexes have been largely used in the area of electrocatalysis (Galal, 1998; Wu et al., 1996). Owing to the reversible redox activity and catalytic properties of vanadium-salen complexes, they have been used in electrocatalytic oxidation of dipyrone (Teixeira et al., 2004) and L-dopa (Teixeira et al., 2004). In the present work, the preparation and electrochemical properties of a carbon paste electrode modified with an oxovanadium (IV) Schiff base complex (VOx) for voltammetric determination of MMZ is discussed. Carbon-paste is a well-known substrate for incorporation of modifiers, as a simple and easy renewing material to construct a modified electrode (Kalcher et al., 1995).

The modified electrode showed good sensitivity in the determination of $\mathrm{MMZ}$, and a long life time without significant decrease in its response. It was successfully applied to the determination of MMZ in tablets.

\section{MATERIALS AND METHODS}

\section{Chemicals}

The VOx (Scheme 1) was synthesized in Yasuj University, Yasuj, Iran. The procedures for preparation and structural identification of VOx were described in literature (Kianfar et al., 2011; Liu and Anson., 2001). Briefly, the vanadyl complex was synthesized by refluxing a methanolic solution of the Schiff base ligand and vanadylacetylacetonate. The reaction was continued for $2 \mathrm{~h}$ until a green precipitate was obtained. It was filtered, washed with methanol and dried in vacuum.

Pure powder of MMZ was a gift from Osvah Pharmaceutical Company (Tehran, Iran). Sodium hydrogenphosphate and hydrochloric acid (both from Fluka) were used to prepare the buffer solution. All other reagents were of analytical grade from Merck (Darmstadt, Germany) and were used without further purification. Doubly distilled water was used for preparation of aqueous solutions. A standard MMZ stock solution $\left(1.0 \times 10^{-3} \mathrm{M}\right)$ was prepared from the pure powder and stored at $4^{\circ} \mathrm{C}$. The working solutions were freshly prepared by serial dilution of the stock solution with $0.1 \mathrm{M}$ phosphate buffer saline (PBS, pH 3).

\section{Apparatus}

The electrochemical measurements were performed using a Potentiostat/Galvanostat $\mu$-Autolab system (Utrecht, The Netherlands). A three-electrode system, including a carbon paste working electrode, a platinum wire as the counter and a saturated calomel reference electrode (SCE) was employed. A Jenway 3345 $\mathrm{pH} / \mathrm{mV}$ meter using a combined glass electrode was used for $\mathrm{pH}$ measurements.

\section{Electrode preparation}

The general procedure to prepare the modified carbon paste electrode was to mix VOx complex $(0.2 \mathrm{~g})$ with graphite powder $(0.8 \mathrm{~g})$
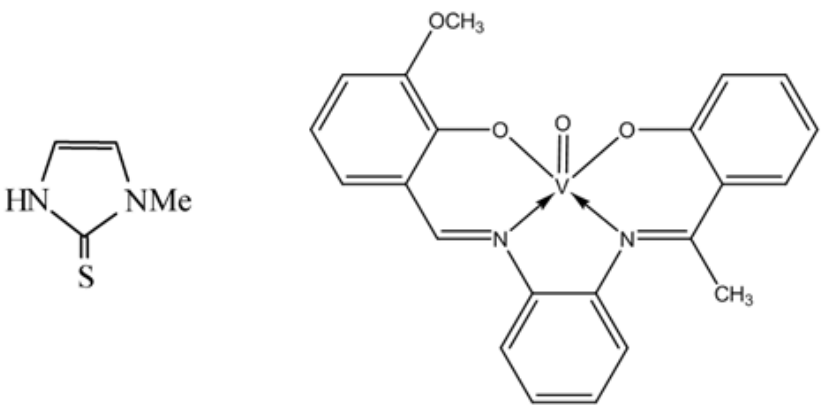

Scheme 1. Chemical structures of $M M Z$ (left) and the oxovanadium Schiff base complex (right).

and mineral oil $(0.2 \mathrm{~g})$. After thorough hand mixing using a mortar and pestle to obtain a very fine paste, the mixture was packed homogeneously in a glass tube. A copper wire was inserted into the carbon paste to implement the electrical conduction. The surface of the modified electrode (VOx/CPE) was finally smoothed manually on a clean filter paper. An unmodified carbon paste electrode was prepared using the same procedure in the absence of VOx complex.

\section{Preparation of real samples}

Ten tablets of MMZ (5 mg/tablet) were weighed and ground to a homogeneous powder. A proper portion of the fine powder (equivalent to $5 \mathrm{mg}$ of MMZ) was carefully weighed and mixed with about $20 \mathrm{ml}$ of PBS buffer $(\mathrm{pH} \mathrm{3} ; 0.1 \mathrm{M})$. The suspension was stirred and heated for $10 \mathrm{~min}$. and then filtered to remove insoluble residue. The clear solution obtained was diluted to $50 \mathrm{ml}$ in a volumetric flask using the same buffer solution.

\section{General voltammetric procedure}

$10 \mathrm{ml}$ of the buffer solution (PBS; $\mathrm{pH} 3 ; 0.1 \mathrm{M}$ ) was transferred to the voltammetric cell. The electrodes were immersed in the solution and after setting the potential range and scan rate, the cyclic voltammogram was recorded. Then a proper portion of $\mathrm{MMZ}$ solution was added to the cell and the stated procedure was repeated.

\section{Evaluation of limit of detection (LOD) and limit of quantitation (LOQ)}

In order to evaluate LOD and LOQ, the voltammetric signal (anodic peak current) was obtained for the buffer solution repeatedly $(n=$ 10) and the mean value $\left(\mathrm{y}_{\mathrm{b}}\right)$ and standard deviation $\left(\mathrm{s}_{\mathrm{b}}\right)$ of the results were obtained. LOD was calculated as a concentration of $M M Z$ which its voltammetric signal was $y_{b}+3 s_{b}$. In the case of $L O Q$, the voltammetric signal should be $y_{b}+10 s_{b}$.

\section{RESULTS AND DISCUSSION}

\section{Electrochemical behaviour of VOx complex}

In order to study electrochemical behaviour of the vanadium complex and due to its insolubility in aqueous solution, the complex was dissolved in acetonitrile. Cyclic 
voltammograms of VOx solution in acetonitrile were recorded at different scan rates (5 to $100 \mathrm{mV} \mathrm{s}^{-1}$ ). The potential range of the working electrode was from 0.0 to $1.0 \mathrm{~V}$ against SCE. As shown in Figure 1, a well resolved pair of anodic and cathodic peaks appeared with a peak separation of about $0.07 \mathrm{~V}$ and $\mathrm{E}_{1 / 2}\left[\left(\mathrm{E}_{\mathrm{pc}}+\mathrm{E}_{\mathrm{pa}}\right) / 2\right]$ of 0.06 $\mathrm{V}$. The ratio of cathodic peak current $\left(\mathrm{I}_{\mathrm{pc}}\right)$ to anodic peak current $\left(I_{p a}\right)$ was about one in the range of scan rates used. These observations confirm a reversible electron transfer mechanism between two oxidation states of vanadium in the complex (Kianfar et al., 2011; Liu and Anson, 2001):

$$
\mathrm{V}^{\mathrm{IV}}-\mathrm{e} \longrightarrow \mathrm{V}^{\mathrm{V}}
$$

As shown in Figure 1, the effect of increasing scan rate is a gradual increase of both anodic and cathodic currents without potential shift which indicates a simple electron transfer mechanism. The anodic peak current increases linearly with the square root of scan rate (Inset), which shows the diffusional nature of the currents (Bard and Faulkner, 2001).

A carbon-paste was modified with VOx (VOx/CPE) and used as the working electrode in cyclic voltammetry. Figure 2 shows the result in aqueous solution (PBS, pH 3). The anodic peak $\left(A_{1}\right)$ and its cathodic counterpart $\left(C_{1}\right)$ observed at the surface of carbon-paste electrode are similar to those observed in acetonitrile solution which correspond to the $\mathrm{V}^{\mathrm{V}} / \mathrm{V}^{\mathrm{IV}}$ couple. Another redox couple $\left(A_{2}\right.$ and $\left.C_{2}\right)$ is observable at higher potentials (about 0.8 $\mathrm{V}$ ) which is due to electron transfer of $\mathrm{V}^{\mathrm{III}} / \mathrm{V}^{\mathrm{IV}}$ couple (Liu and Anson, 2000).

Vanadium (III) is formed in acidic solutions from $\mathrm{V}^{\mathrm{IV}}$ through a disproportionation mechanism as shown in reaction $b$ which is oxidized at the electrode surface:

$$
\begin{aligned}
& 2 \mathrm{~V}^{\mathrm{IV}}+2 \mathrm{H}^{+} \longrightarrow \mathrm{V}^{\mathrm{V}}+\mathrm{V}^{\mathrm{III}}+\mathrm{H}_{2} \mathrm{O} \\
& \mathrm{V}^{\prime \prime I}-\mathrm{e} \longrightarrow \mathrm{V}^{\mathrm{IV}}
\end{aligned}
$$

Both reactions occurred at the surface of the electrode, while Reaction b occurred between the vanadium complex and the aqueous solution, the electron transfer Reaction c was conducted through the electrode. Due to the necessity of acidic conditions for disproportionation, the second pair $\left(A_{2}\right.$ and $\left.C_{2}\right)$ was not observed in acetonitrile solution.

\section{Electrocatalytic effect of VOx on the oxidation of MMZ}

Figure 3 is a comparison between cyclic voltammograms of $\mathrm{MMZ}$ at the surface of an unmodified-carbon-paste electrode and VOx/CPE. As is obvious, in the presence of MMZ, the oxidation peak of $V^{\text {III }}$ significantly increased which may be attributed to the catalytic effect on the oxidation of MMZ to the disulfide product (Aragoni et al.,

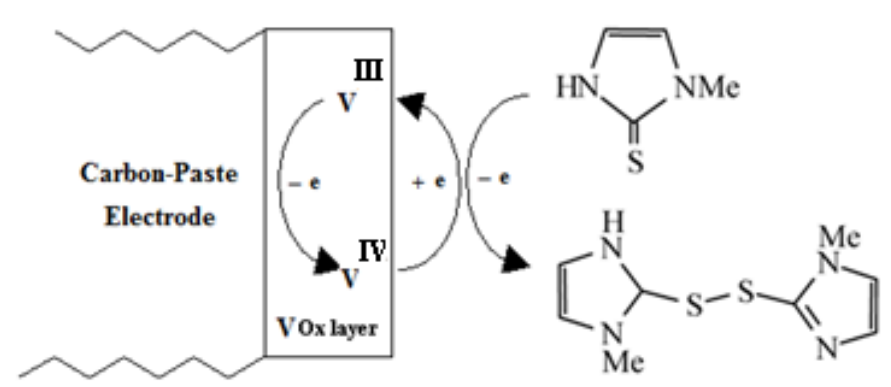

Scheme 2. Representation of electrocatalytic oxidation of MMZ.

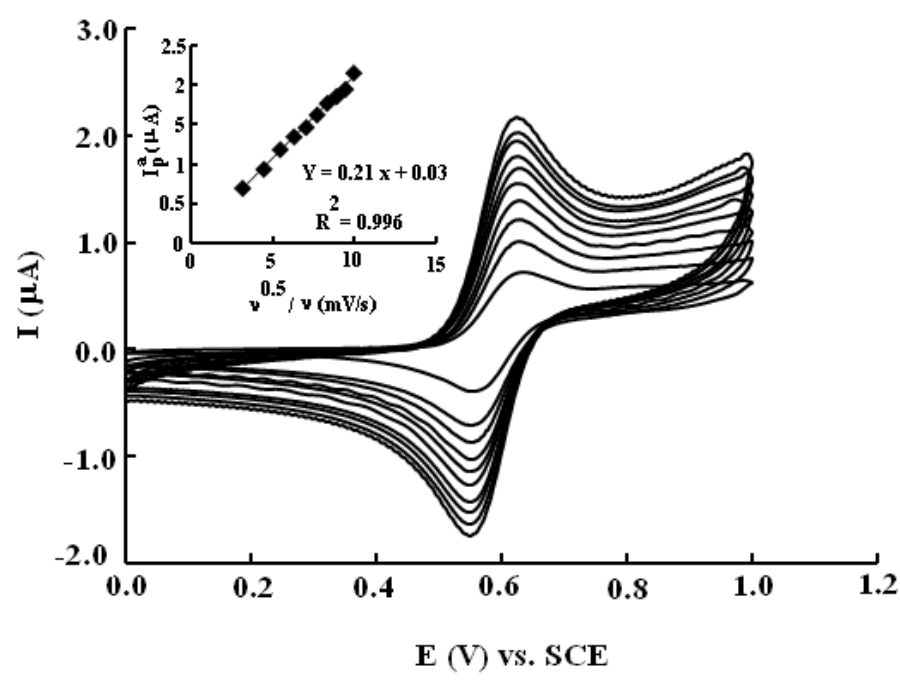

Figure 1. Cyclic voltammograms of VOx complex $\left(1.0 \times 10^{-4} \mathrm{M}\right)$ in acetonitrile on a glassy carbon electrode at various scan rates: from inner to outer, 5, 10, 20,30, 40, 50, 60, 70, 80, 90 and $100 \mathrm{mV} \mathrm{s}^{-1}$. Supporting electrolyte: tetraethylammonium perchlorate $(0.1 \mathrm{M})$.

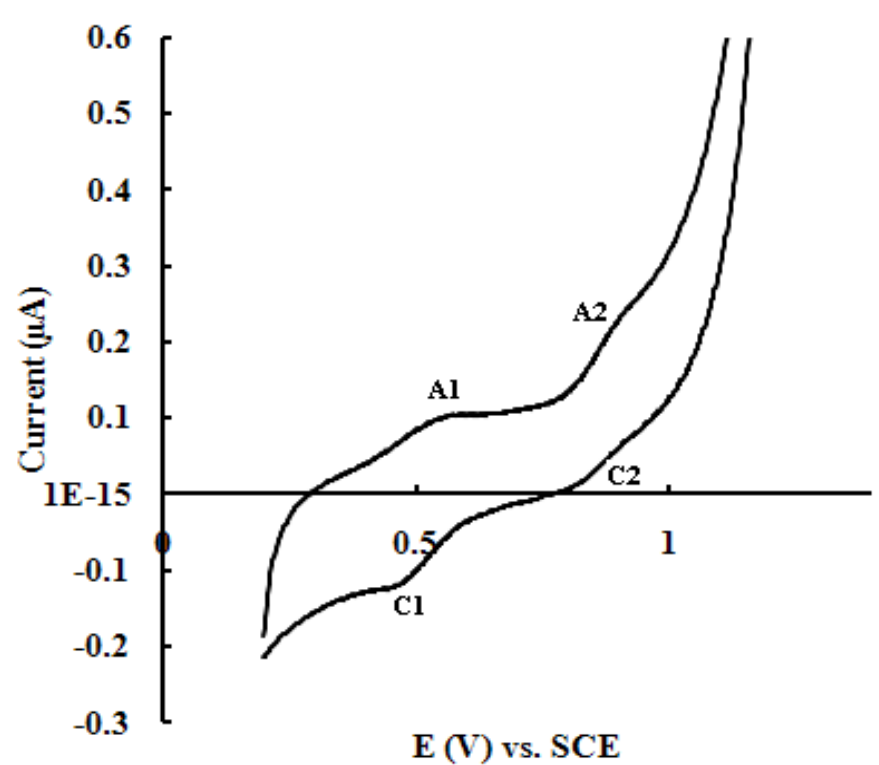

Figure 2. Cyclic voltammogram of $\mathrm{VOx} / \mathrm{CPE}$ in a PBS $(\mathrm{pH} 3,0.1$ M). Scan rate, $50 \mathrm{mV} \mathrm{s}^{-1}$. 


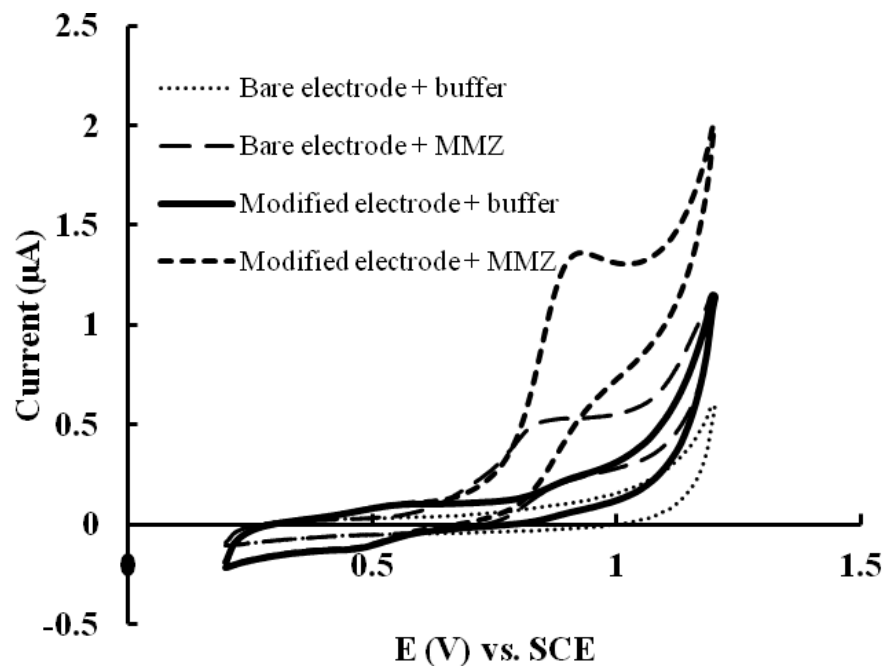

Figure 3. Cyclic voltammograms at a bare carbon-paste electrode (a) in the absence, (b) in the presence of $40 \mu \mathrm{M} \mathrm{MMZ}$; and at $\mathrm{VOx} / \mathrm{CPE}$ (c) in the absence and (d) in the presence of $40 \mu \mathrm{M}$ MMZ; supporting electrolyte, PBS (pH 3.0, $0.1 \mathrm{M})$; scan rate, 50 $\mathrm{mV} \mathrm{s}^{-1}$.

2002). Scheme 2 shows the whole process at the surface of modified electrode in which a dimer is formed between two molecules of $\mathrm{MMZ}$ as the oxidation product.

Although MMZ was oxidizable at the surface of unmodified electrode (Figure 3 ) but the anodic current was much weaker than the electrocatalytic current at VOx/CPE.

The effect of $\mathrm{pH}$ of the solution on electrocatalytic peak current was studied. The anodic current decreased with increasing $\mathrm{pH}$ from 3.0 to 7.0 because protons are involved in the disproportionation reaction (Reaction $b$ ) to produce $\mathrm{V}^{\mathrm{III}}$. A $\mathrm{pH}$ of 3.0 was selected for the electrocatalytic oxidation of $\mathrm{MMZ}$.

The effect of different scan rates (10 to $200 \mathrm{mV} \mathrm{s}^{-1}$ ) on the electrocatalytic current was studied in PBS ( $\mathrm{pH} 3.0)$ solution (Figure 4A). The results showed that the peak current increased linearly with the square root of scan rate (Figure 4B), which demonstrates that the anodic current is controlled by diffusion of $\mathrm{MMZ}$ to the electrode surface (Bard and Faulkner, 2001).

In order to obtain the diffusion coefficient of MMZ to the surface of $\mathrm{VOx} / \mathrm{CPE}$, static chronoamperometry was used. Figure $5 \mathrm{~A}$ shows the chronoamperograms for four different concentrations of MMZ. Diffusion coefficient was obtained from the slopes of the linear plots of currents (I) against $\mathrm{t}^{-1 / 2}$ (Figure $5 \mathrm{~B}$ ) according to Cottrell equation:

$I=n F A D^{1 / 2} C^{*} / \pi^{1 / 2} t^{-1 / 2}$

Where $D$ and $C^{*}$ are the diffusion coefficient and the bulk concentration of MMZ, respectively. $A$ is the geometric area of the carbon-paste electrode, $t$ is the time elapsed,

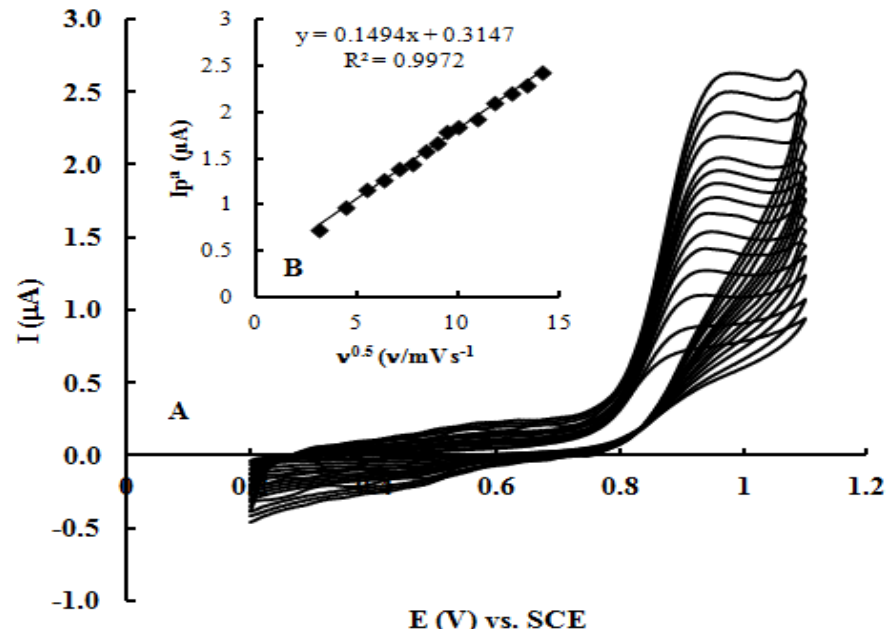

Figure 4. (A) Cyclic voltammetric responses at different scan rates using $\mathrm{VOx} / \mathrm{CPE}$ as the working electrode. [MMZ] $=40 \mu \mathrm{M}$; supporting electrolyte, phosphate buffer $(\mathrm{pH} 3.0,0.1 \mathrm{M})$; Scan rates from down to top: $10,20,30,40,50,60,70,80,90,100,110,120$, $130,140,150,160,170,180$ and $200 \mathrm{mV} \mathrm{s}^{-1}$. (B), variation of the catalytic current versus the square root of scan rate.

and $\mathrm{n}$ is the number of electrons in the electrode process which is 1 in this case.

An average amount of $1.24 \times 10^{-4} \mathrm{~cm}^{2} \mathrm{~s}^{-1}$ for $\mathrm{D}$ was obtained (Figure $5 \mathrm{C}$ ). The rate constant for the chemical reaction between MMZ and redox sites in VOx/CPE, $\mathrm{k}$, can be evaluated by chronoamperometry according to equation 2 (Galus, 1976):

$I_{C} / I_{L}=\pi^{1 / 2}\left(k C^{*} t\right)^{1 / 2}$

Where $I_{C}$ is the catalytic current in the presence of $M M Z$, $I_{L}$ is the limited current in the absence of MMZ, and $k$ is the catalytic rate constant $\left(\mathrm{cm}^{3} \mathrm{~mol}^{-1} \mathrm{~s}^{-1}\right)$. The calculated value of $\mathrm{k}$ was $1.13 \times 10^{7} \mathrm{~cm}^{3} \mathrm{~mol}^{-1} \cdot \mathrm{s}^{-1}$ using the slope of the plot of $I_{C} / I_{L}$ against $t^{1 / 2}$ (Figure $5 \mathrm{D}$ ). The large value of $k$ indicates a fast electron transfer reaction between $M M Z$ and $\mathrm{V}^{\prime \prime \prime}$ ions.

\section{Analytical aspects}

\section{Determination of $M M Z$}

It was observed that the amount of catalytic current in cyclic voltammetry was proportional to the MMZ concentration. Since differential pulse voltammetry (DPV) has a higher sensitivity, it was used for the determination of MMZ. Figure 6A shows DPVs for various concentrations of $\mathrm{MMZ}$ on the surface of VOx/CPE.

The voltammetric calibration curve for the determination of $\mathrm{MMZ}$, shown in Figure $6 \mathrm{~B}$, has a linear range from 0.9 to $100 \mu \mathrm{M}$ with a LOD of $0.8 \mu \mathrm{M}$ and $\mathrm{LOQ}$ 


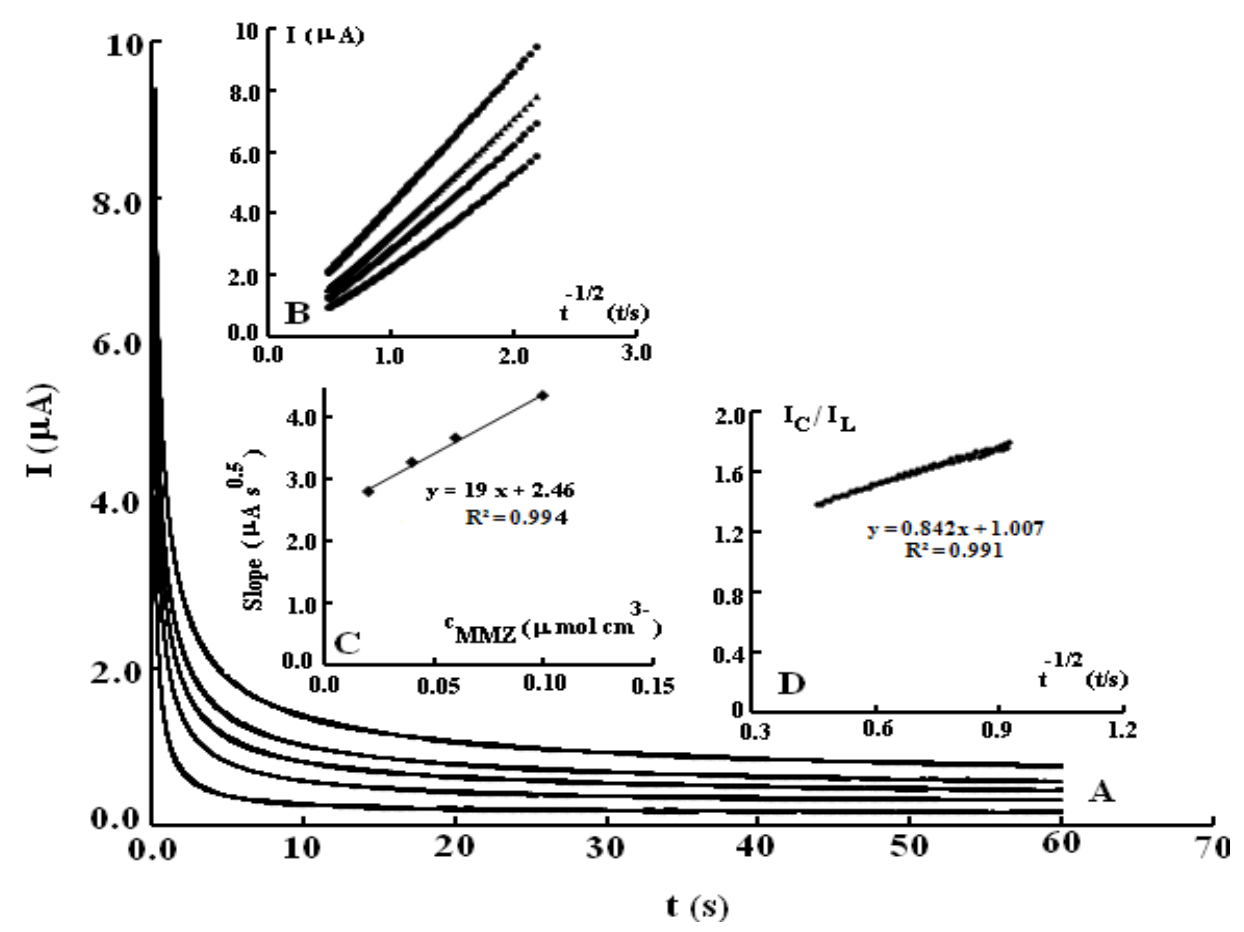

Figure 5. (A) Chronamprograms obtained for VOx/CPE in the absence and presence of 20, 40, 60 and $100 \mu \mathrm{M} \mathrm{MMZ}$ in $0.1 \mathrm{M}$ phosphate buffer. B) Cottrell plots for 20, 40, 60, and 100 $\mu \mathrm{M} M M Z$. C) Dependence of slopes of Cottrell plots on concentration of MMZ. D) $I_{C} / I_{L}$ versus $t^{1 / 2}$.

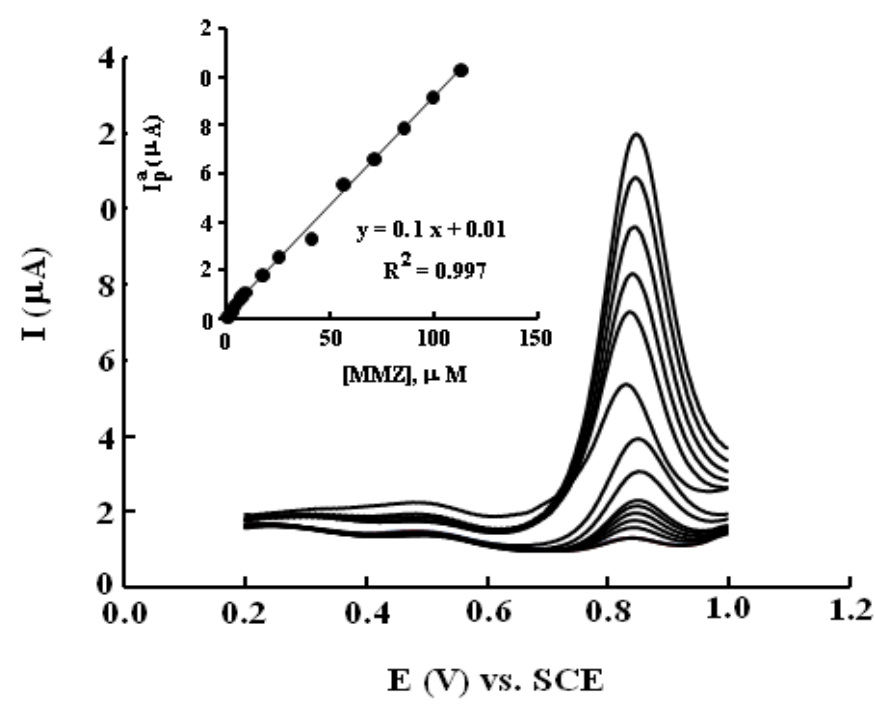

Figure 6. A) Differential pulse voltammograms for different concentrations of $\mathrm{MMZ}$ at $\mathrm{VOx} / \mathrm{CPE}$. [methiamazole]: 0.9, 2.7, 4.4, 6.0, 7.6, 9.2, 17.4, 25.4, 41.1, 56.3, 71.1, 85.4, 99.2 and 112 $\mu \mathrm{M}$ in $0.1 \mathrm{M}$ PBS ( $\mathrm{pH} 3.0$ ). B) Plot of electrocatalytic peak currents versus $M M Z$ concentration.

of $2.63 \mu \mathrm{M}$. The slope and the correlation coefficient $\left(r^{2}\right)$ for the least squares line were $0.1 \mu \mathrm{A} / \mu \mathrm{M}$ and 0.997 , respectively. The relative standard deviation (RSD) for four replicate measurements of $20 \mu \mathrm{M}$ of $\mathrm{MMZ}$ under optimum conditions was $1.76 \%$. The results are comparable (Shahrokhian and Ghalkhani, 2008) or better than (Aslanoglu and Peker, 2003) the literature reports on the electrochemical determination of MMZ. The electrode could be used several times without significant lose of current response. Before each experiment the electrode was simply washed with distilled water.

\section{Interferences}

Under optimum conditions, the interference effect of some organic compounds which may be present in real samples of MMZ was studied. A concentration of $5 \mu \mathrm{M}$ of $M M Z$ was used and the suspicious compound was added. The tolerance limit of interferent was defined as an amount of it that retains the electrocatalytic current between 95 to $105 \%$ of its initial amount in the absence of interferent. The results show that 150 -fold of amino acids asparagine, D, L-alanine, L-histidine and 40-fold glucose in the solution had almost no influence on the determination of MMZ.

\section{Determination of MMZ in pharmaceutical preparations}

In order to demonstrate the capability of VOx/CPE to the electrocatalytic quantitation of $M M Z$ in real samples, 
Table 1. Determination of MMZ in tablet samples.

\begin{tabular}{cccc}
\hline Sample & $\mathbf{M M Z}\left(\mathrm{mol} \mathrm{L}^{-1}\right)$ & Found $\left(\mathrm{mol} \mathrm{L}^{-1}\right)$ & Recovery $\%$ \\
\hline 1 & $3.8 \times 10^{-6}$ & $3.6 \times 10^{-6}$ & 95 \\
2 & $5.7 \times 10^{-6}$ & $5.3 \times 10^{-6}$ & 93 \\
\hline
\end{tabular}

tablets of MMZ ( $5 \mathrm{mg} \mathrm{MMZ} \mathrm{per} \mathrm{tablet)} \mathrm{were} \mathrm{used} \mathrm{as} \mathrm{real}$ samples. The calibration curve was plotted using the standard MMZ solutions and the amount of the drug in tablet was calculated by using the regression line equation. The results for the analysis of two different aliquots of the tablet solution are shown in Table 1. As it is shown, the recoveries are quite satisfactory and the modified electrode VOx/CPE can be successfully applied in the analysis of trace amounts of $M M Z$ in pharmaceutical preparations.

\section{Conclusions}

In the present article, a VOx was used in the bulkmodification of a carbon-paste electrode. Cyclic voltammetry in PBS $(\mathrm{pH} 3)$ showed two redox couples for the vanadium complex, that is, $\mathrm{V}^{\mathrm{IV}} / \mathrm{V}^{\mathrm{V}}$ and $\mathrm{V}^{\mathrm{II}} / \mathrm{V}^{\mathrm{IV}}$ couples, in which $\mathrm{V}^{\mathrm{III}}$ was produced by a disproportionation chemical reaction in acidic solution. The modifier showed an excellent electrocatalytic activity towards the oxidation of MMZ through the second redox couple, that is, $\mathrm{V}^{\prime \prime \prime} / \mathrm{V}^{\mathrm{IV}}$. The diffusion coefficient of MMZ and the rate constant of the catalytic chemical reaction were calculated using chronoamperometry. DPV was used in the determination of $\mathrm{MMZ}$ in pharmaceutical preparations. The results were quite satisfactory. Ease of preparation of the modified electrode and the simple renewal procedure of it, as well as good reproducibility of the voltammetric responses make it an efficient sensor for the detection of trace amounts of MMZ in pharmaceutical samples.

\section{REFERENCES}

Aragoni MC, Arca M, Demartin F, Devillanova FA, Garau A, Isaia F, Lippolis V, Verani G (2002). Anti-thyroid drug methimazole: X-ray characterization of two novel ionic disulfides obtained from its chemical oxidation by $\mathrm{I}_{2}$. J. Am. Chem. Soc. 124:4538-4539.

Aslanoglu M, Peker N (2003). Potentiometric and voltammetric determination of Methimazole. J. Pharm. Biomed. Anal. 33:1143-1147.

Bard AJ, Faulkner LL (2001). Electrochemical methods, Fundamentals and applications, 2nd ed. Wiley, New York.

Blanchflower WJ, Hughes PJ, Cannavan A, McCoy MA, Kennedy DG (1997). Determination of thyreostats in thyroid and urine using highperformance liquid chromatography-atmospheric pressure chemical ionisation mass spectrometry. Analyst 122:967-972.
Dong F, Hu K, Han H, Liang J (2009). A novel method for methimazole determination using CdSe quantum dots as fluorescence probes. Microchim. Acta. 165:195-201.

Economou A, Tzanavaras PD, Notou M, Themelis DG (2004). Determination of methimazole and carbimazole by flow-injection with chemiluminescence detection based on the inhibition of the $\mathrm{Cu}(\mathrm{II})$ catalysed luminol-hydrogen peroxide reaction. Anal. Chim. Act. 505:129-133.

Edward AC (1992). In: Reynard AM, Smith CM (eds.), Textbook of Pharmacology. Saunders, Philadelphia. p 652.

Galal A (1998). Electrocatalytic oxidation of some biologically important compounds at conducting polymer electrodes modified by metal complexes. J. Solid State Electrochem. 2:7-15.

Galus Z (1976). Fundamentals of electrochemical analysis. Ellis Horwood, New York.

Jovanovic T, Stankovic B, Koricanac Z (1992). Spectrophotometric determination of thiamazole (methimazole) in water and pharmaceutical dosage form. Pharmazie. 47:798.

Kalcher K, Kauffmann JM, Wang J, Švancara I, Vytřas K, Neuhold C, Yang Z (1995). Sensors based on carbon paste in electrochemical analysis: A review with particular emphasis on the period 1990-1993. Electroanalysis. 7:5-22.

Kianfar AH, Sobhani V, Dostani M, Shamsipur M, Roushani M (2011). Synthesis, spectroscopy, electrochemistry and thermal study of vanadyl unsymmetrical Schiff base complexes. Inorg. Chim. Acta. 365:108-112.

Kusmierek K, Bald E (2007). Determination of methimazole in urine by liquid chromatography. Talanta. 71:2121-2125.

Liu Z, Anson, FC (2000). Electrochemical Properties of Vanadium(III,IV,V)-Salen Complexes in Acetonitrile. Four-Electron Reduction of $\mathrm{O}_{2}$ by V(III)-Salen. Inorg. Chem. 39:274-280.

Liu Z, Anson FC (2001). Schiff base complexes of vanadium(III, IV, V) as catalysts for the electroreduction of $\mathrm{O}_{2}$ to $\mathrm{H}_{2} \mathrm{O}$ in acetonitrile. Inorg. Chem. 40:1329-1333.

Shahrokhian S, Ghalkhani M (2008). Voltammetric Determination of methimazole using a carbon paste electrode modified with a Schiff base complex of cobalt. Electroanalysis. 20:1061-1066.

Sheng Z, Han H, Yang G (2011). A novel method for sensing of methimazole using gold nanoparticle-catalyzed chemiluminescent reaction. Luminescence 26:196-201.

Teixeira MFS, Bergamini MF, Marques CMP, Bocchi N (2004). Voltammetric determination of L-dopa using an electrode modified with trinuclear ruthenium ammine complex (Ru-red) supported on $\mathrm{Y}$ type zeolite. Talanta 63:1083-1088.

Teixeira MFS, Marcolino-Junior LH, Fatibello O, Dockal ER, Cavalheiro ETG (2004). Voltammetric determination of dipyrone using a $N, N^{\prime}$ ethylene bis (salicylideneaminato) oxovanadium(IV) modified carbonpaste electrode. J. Braz. Chem. Soc. 15:803-808.

Wu Q, Maskus M, Pariente F, Tobalina F, Fernández VM, Lorenzo E, Abruña HD (1996). Electrocatalytic oxidation of NADH at glassy carbon electrodes modified with transition metal complexes containing 1,10-phenanthroline-5,6-dione ligands. Anal. Chem. 68:3688-3696.

Xi X, Ming L, Liu J (2010). Electrochemical determination of thiamazole at a multi-wall carbon nanotube modified glassy carbon electrode. J. Appl. Electrochem. 40:1449-1454.

Yazhen W (2011). Electrochemical determination of methimazole based on the acetylene black/chitosan film electrode and its application to rat serum samples. Bioelctrochem. 81:86-90. 